
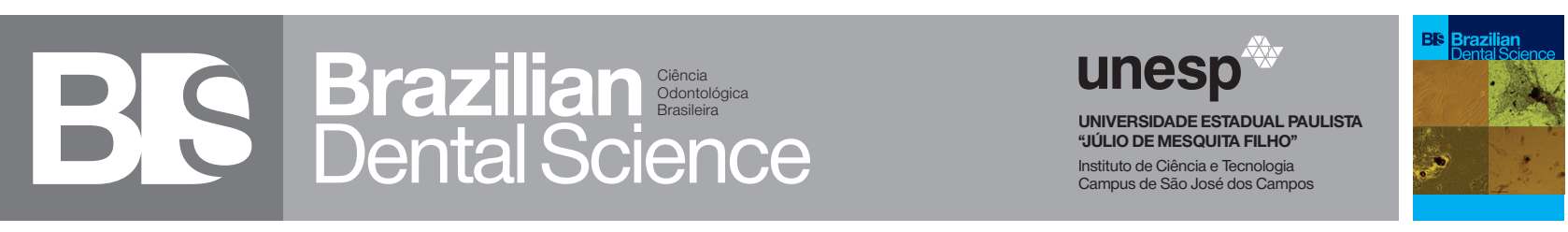

\title{
Shear Bond Strength of Composite Repair System to Bilayered Zirconia Using Different Surface Treatments (In Vitro Study)
}

Resistência ao cisalhamento de reparos de resina composta e zircônia bicamada usando diferentes tratamentos de superfície (estudo in vitro)

\author{
Ahmed A. BAIOMY ${ }^{1}$, Jihan F. YOUNIS ${ }^{1}$, Ahmed H. KHALIL ${ }^{2}$ \\ 1 - Department of Fixed Prosthodontics - Faculty of Oral and Dental Medicine - Misr International University - Cairo - Egypt. \\ 2 - Department of Fixed Prosthodontics - Faculty of Oral and Dental Medicine - Cairo University - Cairo - Egypt.
}

\section{ABSTRACT}

Objective: the study is aimed to evaluate the effect of different surface treatment methods on shear bond strength between composite repair system and both of zirconia core and veneering porcelain and analyze the mode of failure between composite repair and ceramic surface. Material and methods: 40 Ceramic discs were fabricated with diameter of $7 \mathrm{~mm}$ and 3 $\mathrm{mm}$ thickness and divided according to material into two groups, Zirconia core discs $(n=20)$ and veneering porcelain discs $(n=20)$. Specimens were thermocycled and then each group was subdivided according to surface treatment method into 4 equal sub groups $(\mathrm{n}=5)$, control subgroup I air abrasion, subgroup II Cojet, subgroup IV combination of cojet and laser surface treatment. Composite blocks were built up and polymerized on the surface of the specimens and shear bond strength of composite to each specimen was tested using a universal testing machine and mode of failure was evaluated using stereomicroscope. Results: Regardless of ceramic type; there was a statistically significant difference between surface treatments. Cojet recorded the highest mean shear bond strength. Laser showed the highest prevalence of adhesive failure. Porcelain + Cojet showed the highest prevalence of cohesive failure. Conclusion: Cojet surface treatment provided superior shear bond strength regardless of the ceramic type whether zirconia or porcelain. Porcelain provided superior shear bond strength values in comparison to zirconia regardless of the surface treatment method tested. Porcelain showed higher percentage of cohesive failure that while the mode of failure in zirconia was most commonly adhesive.

\section{KEYWORDS}

Laser; Porcelain repair; Zirconia repair.

\section{RESUMO}

Objetivo: O objetivo deste estudo foi avaliar o efeito de diferentes métodos de tratamento de superfície na resistência ao cisalhamento de reparos de resina composta e núcleos de zircônia ou cobertura de porcelana, e analisar o modo de falha entre o reparo e a superfície cerâmica. Material e métodos: 40 discos de cerâmica foram fabricados com diâmetro de $7 \mathrm{~mm}$ e $3 \mathrm{~mm}$ de espessura e divididos de acordo com o material em dois grupos, discos de zircônia $(\mathrm{n}=20)$ e discos de porcelana $(\mathrm{n}=20)$. As amostras foram termocicladas e, em seguida, cada grupo foi subdividido de acordo com o método de tratamento de superfície em 4 subgrupos iguais $(\mathrm{n}=5$ ), subgrupo I :controle (abrasão a ar); subgrupo II: Cojet; subgrupo III: laser; subgrupo IV: combinação entre Cojet e tratamento de superfície a laser. Blocos de resina composta foram construídos e polimerizados na superfície das amostras e a resistência ao cisalhamento do compósito para cada amostra foi testada usando uma máquina de teste universal e o modo de falha foi avaliado usando o estereomicroscópio. Resultados: Independentemente do tipo de cerâmica houve diferença estatisticamente significante entre os tratamentos de superfície. Cojet registrou a maior força média de união ao cisalhamento. O laser mostrou a maior prevalência de falha adesiva. Porcelana + Cojet apresentou a maior prevalência de falha coesiva. Conclusão: $O$ tratamento superficial com Cojet proporcionou resistência superior ao cisalhamento, independentemente do tipo de cerâmica, seja zircônia ou porcelana. A porcelana forneceu valores superiores de resistência ao cisalhamento em comparação com a zircônia, independentemente do método de tratamento de superfície testado. A porcelana apresentou maior porcentagem de falha coesiva que enquanto o modo de falha na zircônia era mais comumente adesivo.

\section{PALAVRAS-CHAVE}

Laser; Reparação de porcelana; Reparo de zircônia. 


\section{INTRODUCTION}

$\mathrm{T}$ he modern need for better esthetic restorations has increased especially with latest advances in sciences of materials and in methods and techniques of construction. Concerns regarding biocompatibility of the metal ceramic restorations along with its esthetic qualities provoked the need for development of better all ceramic systems that can provide function and esthetics with no compromises [1].

Reinforcing glass ceramics and introducing tougher materials like zirconia proved to be a good alternative in molar and posterior region and in long span bridges.

However with the need for good esthetic outcome zirconia restorations which had high strength properties did not deliver the ideal optical properties as they are opaque in nature and does not permit passage of the light as natural teeth would allow which necessitates the need for an esthetic solution for this drawback [2].

The first solution was to layer the zirconia framework with a higher translucency material to permit passage of light and mimic the natural teeth shade for better esthetic restorations. The need for esthetics in stress bearing areas lead to the usage of monolithic zirconia to prevent the drawbacks of porcelain chipping The suggested material that can be layered was feldspathic porcelain which come in a form of a powder and a liquid which would be mixed together and layered layer by layer on top of the surface of zirconia and fire it in a specific porcelain oven. The other method was over pressing a pressable ceramic material on top of the surface of zirconia with a higher strength pressable ceramic material [1-3].

Due to the chemistry and the composition of the zirconia, it has weak bonding properties to other materials as the veneering porcelain. Other reasons suggested for the fractured veneering porcelain is the improper technique of manufacturing and layering as the layer thickness of porcelain exceeded the thickness of $2 \mathrm{~mm}$ and left unsupported porcelain which was prone to fracture.

The high fracture rate of the veneering porcelain of zirconia frameworks compared to porcelain fused to metal restorations necessitates the need for research into repair and finding a faster and efficient means for repairing zirconia.

Methods of repair are divided into repair immediately at the clinic or repair at the lab by adding new layers of porcelain .Immediate repair in the clinic is the most favorable as it will save chair time and patients time. Immediate repair in the clinic comprises the use of different surface treatment methods to increase the roughness of the surface and increase the amount of shear bond strength. Laser surface treatment recently was used as a new method to increase surface roughness of the ceramics and to improve the bond strength during intraoral repair to be a more practical option rather than surface treatments as air abrasion or silica coating [3].

Composite resin is the material used for immediate repair of fractured veneering porcelain with the use of silane coupling agent to promote good bond strength between fractured porcelain or framework and the composite resin. The choice of composite resin is due to its ability to bond and its esthetic properties $[2,4]$.

The aim of this study is to investigate the effect of different surface treatments which are air abrasion, Cojet, laser irradiation and combination of Cojet and laser irradiation on shear bond strength between composite repair system and both of zirconia core and veneering porcelain.

\section{MATERIAL AND METHODS}

\section{Sample Size Calculation}

In this study power analysis was performed for a $2 \times 2$ fixed effects analysis of variance; the first factor (Ceramic type) includes 2 levels and the second factor (Repair system) includes 4 levels. Based upon the results of Akyil MS et al. (2010) [1] and Uzun IH et al.(2017) [2], using alpha ( $\alpha$ ) level of $0.05(5 \%)$ and Beta $(\beta)$ level of $0.20(20 \%)$ i.e. power $=80 \%$; the minimum estimated sample size was 5 samples per subgroup giving a total of 40 samples. Sample size calculation was performed using IBM ${ }^{\circledR}$ SPSS $₫$ Sample Power @ Release 3.0.1.

\section{Sample preparation}

Forty Ceramic discs were fabricated with diameter of $7 \mathrm{~mm}$ and $3 \mathrm{~mm}$ thickness and divided according to material into two groups, Zirconia core discs $(n=20)$ and veneering porcelain discs $(\mathrm{n}=20)$. Specimens will be thermocycled and then each group will be subdivided according to surface treatment method into 4 equal sub groups $(n=5)$, control subgroup I air abrasion, subgroup II Cojet, subgroup III laser, subgroup IV combination of air abrasion and laser surface treatment. Composite blocks were built up and polymerized on the surface of the specimens and shear bond strength of composite to each specimen was tested using a universal testing machine and mode of failure was evaluated using stereomicroscope (Figure 1, Table1). 


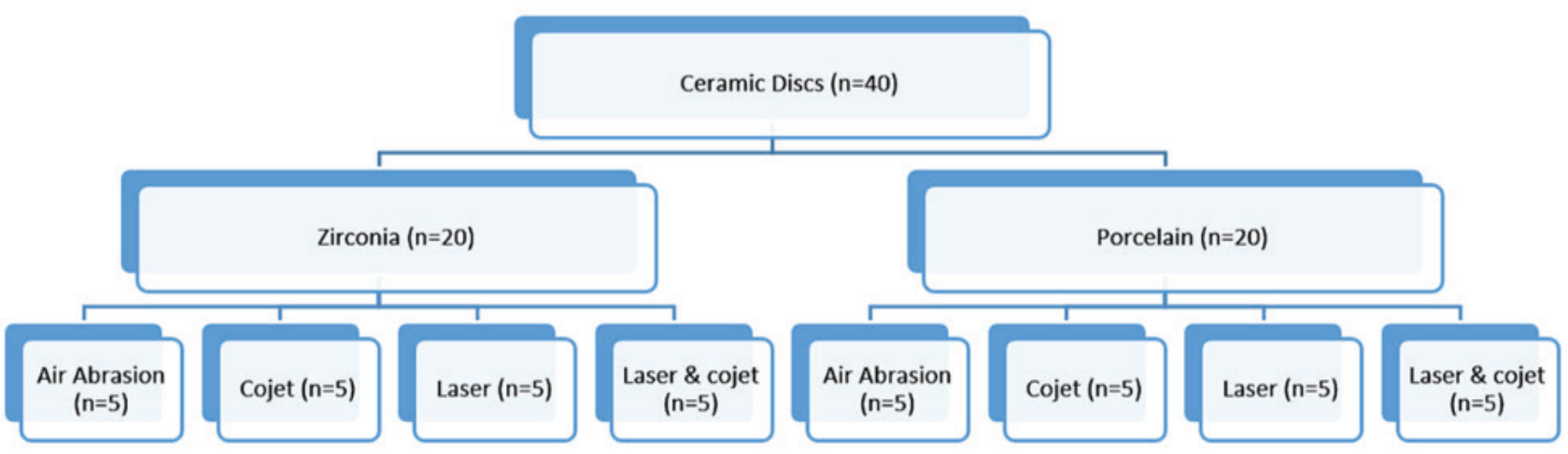

Figure 1 - Showing sample groups and distribution.

Table 1 - Chemical composition of different tested materials

\begin{tabular}{|c|c|c|c|c|}
\hline \multicolumn{2}{|c|}{ Material } & Manufacturer & Chemical Composition & Percentages \\
\hline \multicolumn{2}{|c|}{ Bio ZX2Zirconium } & Dental Direkt GmbH, Germany & $\begin{array}{l}\text { Zirconium oxide } \\
\text { Aluminum oxide } \\
\text { Yttrium oxide } \\
\text { Hafnium oxide }\end{array}$ & $\begin{array}{l}70-100 \% \\
0-1 \% \\
3-15 \% \\
1-5 \%\end{array}$ \\
\hline \multicolumn{2}{|c|}{ Ceramco PFZ } & Dentsply Sirona, USA & $\begin{array}{c}\text { Sodium Potassium Aluminosilicate } \\
\text { SiO2, Al203, Na20, K20, SnO2, Ce02, Pigments, } \\
\text { 1.3-Butanedio Xi }\end{array}$ & NA \\
\hline \multicolumn{2}{|c|}{ Clearfil AP-X composite } & $\begin{array}{l}\text { Kuraray Noritake Dental Inc, } \\
\text { Japan }\end{array}$ & $\begin{array}{l}\text { bisphenol A diglycidylmethacrylate } \\
\text { triethylene glycol dimethacrylate } \\
\text { Silanated barium glass filler } \\
\text { Silanated silica filler } \\
\text { Silanated colloidal silica } \\
\text { dl-Camphorquinone } \\
\text { Catalysts } \\
\text { Accelerators } \\
\text { Pigments }\end{array}$ & $\begin{array}{l}\quad<12 \% \\
<5 \% \\
\text { not mentioned } \\
\text { notmentioned } \\
\text { not mentioned } \\
\text { notmentioned } \\
\text { notmentioned } \\
\text { not mentioned } \\
\text { notmentioned }\end{array}$ \\
\hline \multirow{4}{*}{$\begin{array}{c}\text { Bisco Intraoral Repair } \\
\text { Kit }\end{array}$} & Porcelain Primer & Bisco Dental Inc, USA & $\begin{array}{l}\text { Ethanol } \\
\text { Acetone } \\
\text { Silane }\end{array}$ & $\begin{array}{c}30-50 \% \\
30-50 \% \\
1-5 \%\end{array}$ \\
\hline & Porcelain etchant & Bisco Dental Inc, USA & $\begin{array}{l}\text { Polyacrylamidomethylpropane sulfonic acid } \\
\text { hydrofluoric acid,aqueous solutions }\end{array}$ & $\begin{array}{l}50-70 \% \\
10-30 \%\end{array}$ \\
\hline & Z-PrimePlus & Bisco Dental Inc,USA & $\begin{array}{c}\text { Ethanol } \\
\text { Bisphenol A Diglycidylmethacrylate } \\
\text { 2-Hydroxyethyl Methacrylate } \\
\text { Proprietary } \\
\text { MDP }\end{array}$ & $\begin{array}{l}75-85 \% \\
5-10 \% \\
5-10 \% \\
1-5 \% \\
1-5 \%\end{array}$ \\
\hline & Porcelain bonding resin & Bisco Dental Inc,USA & $\begin{array}{c}\text { Urethane Dimethacrylate } \\
\text { BisGMA } \\
\text { Tetrahydrofurfuryl Methacrylate } \\
\text { Trimethylolpropane Trimethacrylate }\end{array}$ & $\begin{array}{c}10-30 \% \\
10-30 \% \\
10-30 \% \\
1-5 \%\end{array}$ \\
\hline
\end{tabular}


Manufacturing the zirconia discs was done by cad cam machine (Vhf S1, vhf camfacture AG, Lettenstraße 10, 72119 Ammerbuch, Germany) used to mill the discs and after milling all excess support sprues were removed and the discs were sintered in a sintering oven (Roko Tytan Zr II, Poland) according to manufacturer instructions. Porcelain discs were manufactured by designing a wax mold which was milled with cad cam machine (Vhf S1, vhf camfacture AG, Lettenstraße 10, 72119 Ammerbuch, Germany) and poured in with a refractory material (Norivest Kuraray,Japan) to make a refractory mold for porcelain application to make porcelain discs.

\section{finishing}

Sample surface standardization and

A 3d printed carrier was designed and 3d printed from polylactic acid material ( PLA) to act as a carrier to hold the discs in place while moving them against the sandpaper to allow to standardize their surface with sandpapers. To ensure standard surface topography of all discs and surface finish, four sandpapers of different grit sized $(600,800,100,1200)$ were used and a special $3 \mathrm{~d}$ printed holder was printed to hold all discs (Figure 2) [3].

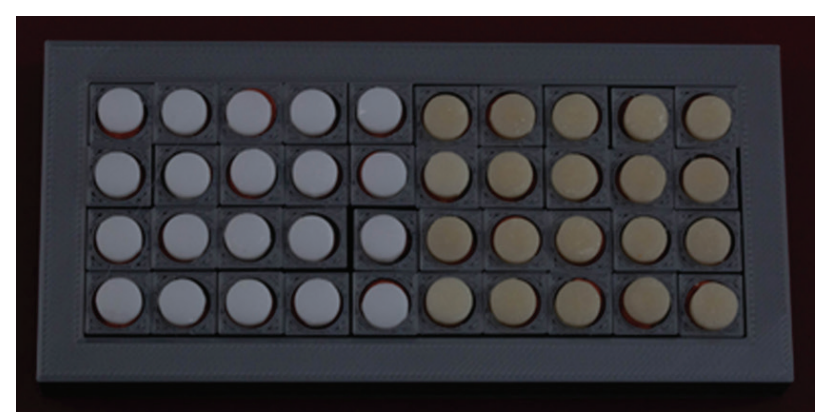

Figure 2 - 3d Printed holder for the samples to be ready for sanding procedure.

\section{Ageing Process}

To simulate clinical condition of ageing, all specimens were thermocycled (1000 cycles) between $5^{\circ} \mathrm{C}-55{ }^{\circ} \mathrm{C}$ with a dwell time of 30 seconds in distilled water bath and a transfer time of 10 seconds before surface treatment in a thermos-cycling unit (Julabo FT200, Julabo, Seelbach, Germany).

\section{Randomization}

After thermocycling, an online research randomization software (randomizer.org) was used to allocate each sample to its designated testing group randomly.

\section{Surface Treatment}

Air Abrasion: air abrasion was done by pressing on the foot control to allow air pressure of 2.8 bar and Air particle abrasion method was performed using $50 \mu$ grain sized aluminum oxide powder for 10 seconds duration. A standardization device (device A) was designed and $3 \mathrm{~d}$ printed to ensure the uniform distance and angle between ceramic disk and nozzle of the air abrasion device (Figure 3) [1].

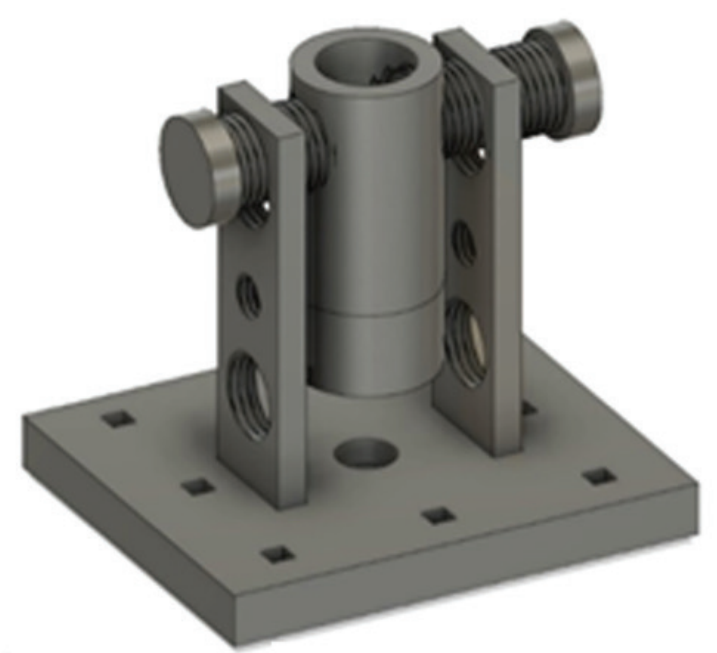

Figure 3 - Device A to standardize the distance and angle of air abrasion tip to the ceramic disc. 
Cojet: Air flow at a pressure of 2.8 bar was allowed for 15 seconds to allow the Cojet particles to blast the surface of the discs. A standardization device (Device B) was designed and $3 \mathrm{~d}$ printed to ensure uniform and correct distance and angle between tip of the Cojet hand piece and the ceramic surface (Figure 4) [1].

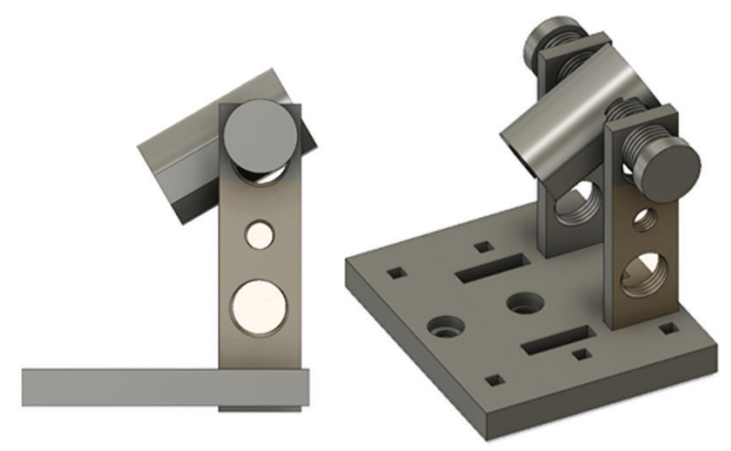

Figure 4 - Device B to standardize the distance and angle of Cojet device to the ceramic surface.

Laser: Laser irradiations of the discs was performed by Er,Cr:YSGG laser device (Waterlase; Biolase Technology, San Clemente, CA, USA) at power outputs of $3 \mathrm{~W}$, with a 2780-nm wavelength at a pulse duration of $140 \mu \mathrm{s}$, and fixed repetition rate of $50 \mathrm{~Hz}$ for $50 \mathrm{sec}$ at a distance of $1 \mathrm{~mm}$ by the same operator in sweeping motion . The laser beam was delivered by the $800-\mu$ m diameter MZ8 tip. This laser irradiation was accomplished under an air/water (56/55) cooling system [4-8].

Laser and Cojet: Laser was first applied with the same parameters as in laser group and after that Cojet sand was applied with the same parameters as in Cojet group. The order of the application was Cojet followed by Laser application [8].

Sample Cleaning: All discs were cleaned in ultrasonic cleaner following the step of surface treatment for 10 minutes followed by steam cleaning for 10 seconds and air-drying using oil free air stream.

\section{Preparing the discs for adhesive procedure}

After surface treatment and cleaning procedures, all the discs were fixed in a rubber based plate for easier handling. Discs were divided into 4 plates and each plate contain 5 discs in their carriers. Surface of the samples were cleaned using phosphoric acid supplied in the intraoral repair kit for 15 seconds. After cleaning with phosphoric acid, the discs were cleaned thoroughly in ultrasonic cleaner for 1 minutes followed by steam cleaning and drying in oil free air flow for 5 seconds per disc $[1-3,8]$

\section{Composite application}

A square PLA mold with an internal hole of $8 \mathrm{~mm}$ diameter and height of $3 \mathrm{~mm}$ was used as a guide for the blade to cut a transparent polyethylene tube with an internal diameter of $5 \mathrm{~mm}$ and external diameter of $8 \mathrm{~mm}$ which was used for packing composite to the surface of the discs. Z prime (in case of zirconia discs) or silane coupling agent (in case of porcelain discs) solution was air dried according to manufacturer's instructions. Bonding resin was applied to the surface of ceramic discs according to the manufacturer instructions. Composite (Clearfil AP-X Esthetics) was used and packed through the polyethylene tube on the surface of the discs in two incremental layers to ensure full curing of the composite with curing time 30 seconds per layer. After complete curing the PLA mold was removed and the polyethylene cylinder was cut from the side and peeled away to avoid exerting any pressure of the samples and composite bonded to it to ensure even stresses at the composite-disc interface Curing of the composite was repeated from the four side walls for 30 seconds per direction with a total of 120 seconds per disc (Figure 5) [1,2]. 


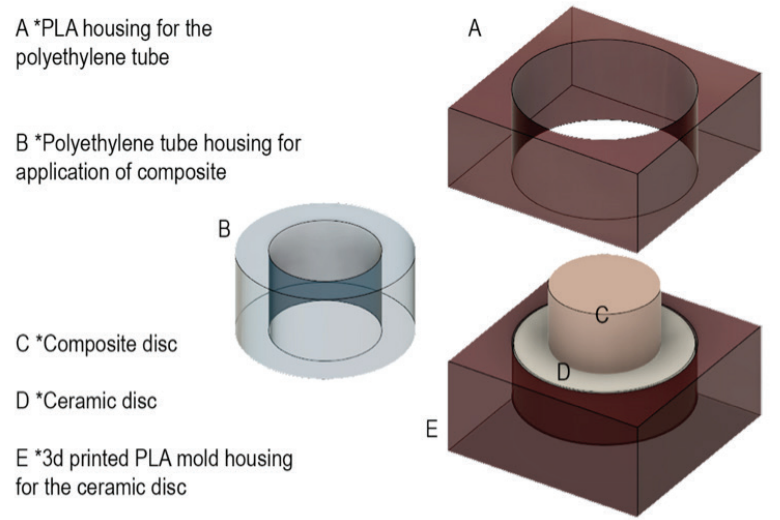

Figure 5 - PLA mold system for application of composite to ceramic surface.

\section{Shear Bond testing}

Universal testing machine (Instron universal testing machine model 3345 England) was used to test shear bond strength. Computer software Bluehill instron version 3.3 was used to record the data. Specimens were mounted to the lower compartment. Monobeveled chisel with a thickness of 0.5 $\mathrm{mm}$ was used to perform the shear bond test in a direction parallel to the surface of the disc and at a crosshead speed of $1 \mathrm{~mm} / \mathrm{min}$. Measurement of shear bond strength values were calculated by converting the loads into MPa by dividing the maximum failure load $(\mathrm{N})$ by the bonding area $(\mathrm{mm} 2)$ saved in excel sheet.[1-3,8]

\section{Mode of failure}

The mode of failure was determined by one operator using stereomicroscope (MA 100 Nikon Japan) using 50x magnification to identify the mode of failure of the tested groups which was classified into:

A- Cohesive failure: failure within the same material whether the composite repair layer or ceramic layer;

B- Adhesive: Failure along the interface between the composite layer and ceramic layer; failure.

\section{RESULTS}

Two-way ANOVA test was used to study the effect of ceramic type, surface treatment and the interaction between the two variables on mean shear bond strength. Bonferroni's post-hoc test was used for pair-wise comparisons. The significance level was set at $\mathrm{P} \leq 0.05$. Statistical analysis was performed with IBM SPSS Statistics for Windows, Version 22.0. Armonk, NY: IBM Corp. Failure mode data (Qualitative data) were presented as frequencies and percentages. Fisher's Exact test was used to compare between the groups. The results showed that ceramic type (regardless of surface treatment) and surface treatment (regardless of ceramic type) had a statistically significant effect on mean shear bond strength. The interaction between the two variables had no statistically significant effect on mean shear bond strength. Since the interaction between the variables is nonstatistically significant, so the variables are independent from each other. Regardless of surface treatment; Zirconia showed statistically significantly lower mean shear bond strength than Porcelain (P-value $<0.001$, Effect size $=$ 0.533) (Table 2, 3) (Figure 6).

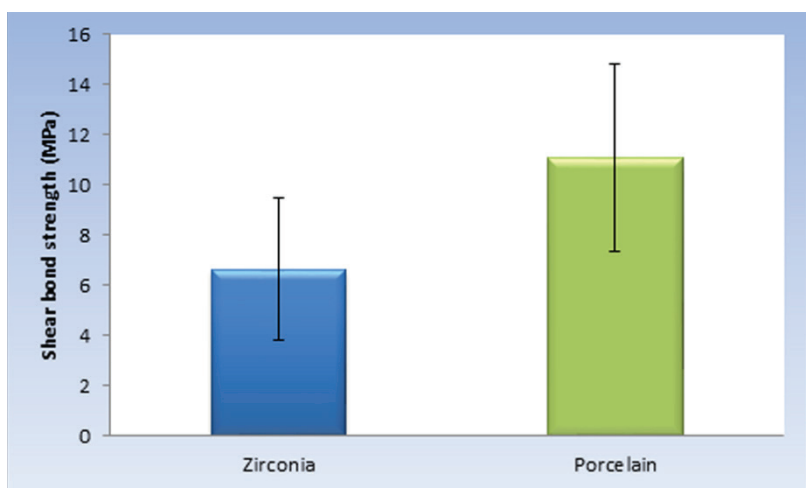

Figure 6 - Bar chart representing mean and standard deviation values for shear bond strength of the two ceramic types regardless of surface treatment. 
Table 2 - Chemical composition of different tested materials

\begin{tabular}{|cccccccc|}
$\begin{array}{c}\text { Source of } \\
\text { variation }\end{array}$ & $\begin{array}{c}\text { Type III } \\
\text { Sum of } \\
\text { Squares }\end{array}$ & df & $\begin{array}{c}\text { Mean } \\
\text { Square }\end{array}$ & F-value & $P$-value & $\begin{array}{c}\text { Effect size } \\
\text { (Partialeta } \\
\text { squared) }\end{array}$ \\
\hline Ceramic type & 193.902 & 1 & 193.902 & 36.459 & $<0.001^{*}$ & 0.533 \\
\hline $\begin{array}{c}\text { Surface treatment } \\
239.434\end{array}$ & 3 & 79.811 & 15.007 & $<0.001^{\star}$ & 0.585 \\
\hline $\begin{array}{c}\text { Ceramic typex } \\
\text { Surface treatment } \\
\text { interaction }\end{array}$ & 6.221 & 3 & 2.074 & 0.390 & 0.761 & 0.035 \\
\hline
\end{tabular}

df: degrees of freedom $=(n-1),{ }^{*}$ : Significant at $P \leq 0.05$

Table 3 - the mean, standard deviation (SD) values and results of two-way ANOVA test for comparison between shear bond strength of the two ceramic types regardless of surface treatment

\begin{tabular}{|c|c|c|c|c|c|}
\hline \multicolumn{2}{|c|}{ Zirconia } & \multicolumn{2}{|c|}{ Porcelain } & \multirow{2}{*}{$P$-value } & \multirow{2}{*}{$\begin{array}{c}\text { Effect size } \\
\text { (Partialeta squared }\end{array}$} \\
\hline Mean & SD & Mean & SD & & \\
\hline 6.65 & 282 & 11.06 & 3.73 & $<0.001^{*}$ & 0.533 \\
\hline
\end{tabular}

*: Significant at $\mathrm{P} \leq 0.05$

\section{Effect of surface treatment regardless of ceramic type}

Regardless of ceramic type Cojet recorded the statistically significantly highest mean shear bond strength. There was no statistically significant difference between Air Abrasion and Laser \& Cojet; Laser showed the lowest mean shear bond strength with nonstatistically significant difference from Laser \& Cojet (Figure 7, Table 4).

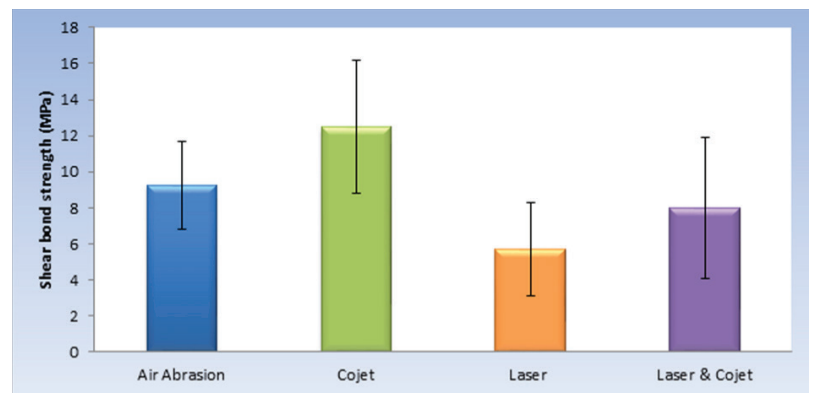

Figure 7 - Bar chart representing mean and standard deviation values for shear bond strength of the four surface treatments regardless of ceramic type.
Table 4 - the mean, standard deviation (SD) values and results of two-way ANOVA test for comparison between shear bond strength distances of the four surface treatments regardless of ceramic type

\begin{tabular}{|c|c|c|c|c|c|c|c|c|c|}
\hline \multicolumn{2}{|c|}{ Air Abrasion } & \multicolumn{2}{|c|}{ Cojet } & \multicolumn{2}{|c|}{ Laser } & \multicolumn{2}{|c|}{$\begin{array}{l}\text { Laser \& } \\
\text { Cojet }\end{array}$} & \multirow{2}{*}{$P$-value } & \multirow{2}{*}{$\begin{array}{c}\text { Effect size } \\
\text { (Partialeta } \\
\text { squared) }\end{array}$} \\
\hline Mean & SD & Mean & SD & Mean & SD & Mean & SD & & \\
\hline $9.25^{\mathrm{B}}$ & 2.41 & $12.48^{\mathrm{A}}$ & 3.71 & $5.71^{\mathrm{C}}$ & 2.56 & $7.99^{\mathrm{Bc}}$ & 3.88 & $<0.001^{\star}$ & 0.585 \\
\hline
\end{tabular}

*: Significant at $P \leq 0.05$, Different superscripts are statistically significantly different

\section{Mode of failure}

There was a statistically significant difference between failure modes in the different groups (P-value $<0.001$, Effect size $=0.699)$. Zirconia + Laser showed the highest prevalence of adhesive failure. Porcelain + Cojet showed the highest prevalence of cohesive failure. Zirconia + Air Abrasion showed the highest prevalence of mixed failure (Figure 8, 9).

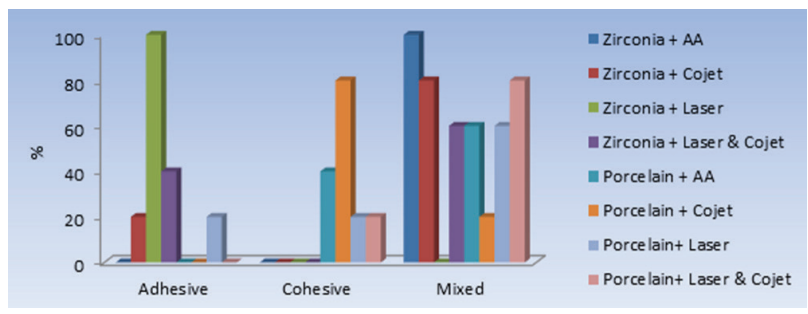

Figure 8 - Bar chart representing failure modes in the different groups.

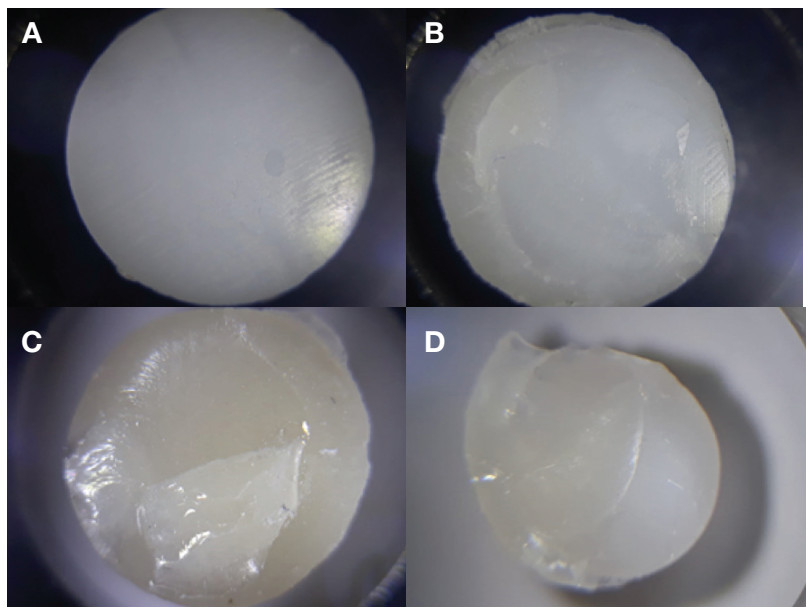

Figure 9 - Different modes of failure (A) Adhesive in zirconia (B) Mixed in zirconia (C) Cohesie in porcelain (D) Mixed in porcelain. 


\section{DISCUSSION}

Zirconia has been used in dental field for many years due to its good strength properties and the ability to withstand stresses during function for long period.

Layering of zirconia has been introduced to add more natural translucent appearance to the restoration .However this layering technique has its drawbacks as the bond between zirconia framework and the overlying porcelain was low and chipping of the overlying porcelain was always a common drawback.

Studies showed that failure that occurred clinically due to delamination of porcelain was $13 \%$ after 3 years and $15.2 \%$ after 5 years $[4,5]$.This study was conducted to evaluate the effect of different surface treatment methods on shear bond strength between either zirconia or feldpsathic porcelain and repair composite resin. Surface treatment methods tested in this study were Laser, Cojet, Air Abrasion, and Laser and Cojet combination.

Airborne abrasion comprises the use of air pressed alumina particles that can have different size ranges as 50 microns and 110 microns which tend to change the topography of the surface. Many studies revealed that air abrasion particles can penetrate up to 15 microns into the substrate surface leading to development of cracks and phase transformation $[6,7]$. In this study the parameters of air abrasion were 2 bar air pressure, the size of the particles were 50 microns and the tip distance from the ceramic surface was $10 \mathrm{~mm}$ for 20 seconds blasting time per ceramic surface. The selection of the parameters was based on the previous study of Barutcigil et al. [8]. The selected particle size and air pressure was recommended to avoid phase transformation of the zirconia or crack creation.

The use of the Cojet intraoral adhesive repair system was introduced by $3 \mathrm{~m}$ company. The usage is by airborne particle abrasion using a chair side abrader for 15 seconds with a small size 30 microns silica modified AL2o3 particles at an air pressure of 3 bar. Cojet results in embedding silica particles inside the surface of the zirconia rendering it more chemically reactive to chemical bonding agents and subsequently increasing bond strength (6).The parameters used with cojet system in this study was 30 microns cojet sand particle size, 2.3 bar air pressure and at a $10 \mathrm{~mm}$ distance from the ceramic surface. The parameters were determined based on previous study [9-11].

In addition to the most common currently used surface treatment methods laser has been introduced modify the surface and for surface treatment of the ceramics. The process of surface treatment comprises very rapid heat change with the free running micro pulse emission causing explosive dislocation of the particles creating irregularities or depressions and micro irregularities. Laser used in this study was Er:Cr YSGG with parameters of $3 \mathrm{~W}$ output power at $50 \mathrm{~Hz}$ frequency based on previous study of Zanjani et al. [10] who evaluated Er:Cr YSGG laser with other different surface treatment methods. It was found that only at $3 \mathrm{w}$ power output can the Er:Cr USGG laser be considered a surface treatment method to create surface roughness and irregularities for better bond strength.

To mimic the clinical condition in the patient's mouth, thermocycling was done by application of 1000 cycles between $5 c$ and $55 \mathrm{c}$ as some reports stated that humidity and oral environment conditions affect the bond strength but not in a statistically significant way [12-14].

After surface treatment method phosphoric acid application along with ultrasonic cleaning was done to ensure the cleanliness of the surface of the specimens by removing contaminations from the surface and to facilitate bonding to composite rather than create roughness as mentioned by In-Hae Han et al. [7]. 
Composite resin was applied to the surface of the discs incrementally and light cured. The composite chosen for the study was Clearfil-AP-X esthetics which is a microhybrid composite. The choice of this type of composite was based on previous studies that implemented it in the repair process and testing the shear bond strength [15-17].

Studies showed that the silica content of porcelain is $50-60 \%$ by weight while in zirconia it is less than $1 \%$ by weight. For this reason silane coupling agent is not effective with zirconia based surface as it contains nearly no silica which are the main component that chemically bond to silane and increase the bond strength. For this reason silane was not used with zirconia discs and was used with feldpsathic discs as they contain enough silica to chemically band with the silane. To achieve chemical bond to zirconia Z-prime was used as it contains phosphate ester monomer 10MDP which chemically bonds with oxide layer of zirconia and increase bond strength [7].

Bond strength in vitro was evaluated using shear testing method by application of load on the bonded composite disc from the side until fracture. Shear bond strength test was selected from other tests as microshear and tensile for its simplicity and clear test protocol and test results can be analyzed rapidly. Monobeveled chisel with a thickness of $0.5 \mathrm{~mm}$ was used to perform the shear bond test in a direction parallel to the surface of the disc and at a crosshead speed of 1 $\mathrm{mm} / \mathrm{min}$ according to ISO/TS 11405:2003. Measurement of shear bond strength values were calculated by converting the loads into MPa by dividing the maximum failure load $(\mathrm{N})$ by the bonding area ( $\mathrm{mm} 2)$ saved in excel sheet.

Regarding the effect of ceramic type: Zirconia showed statistically significantly lower mean shear bond strength than porcelain because of the lack chemically active silica which chemically bonds to composite through silane bonding agent since the silica content of feldspathic porcelain (50-60\% by weight) is higher than zirconia (lower than $1 \%$ by weight) as stated by In-Hae Han et al. [7] which is responsible for higher chemical bond strength to silane and composite resign accordingly

Regarding the effect of surface treatment regardless of the ceramic type: there was a statistically significant difference between surface treatments. Cojet recorded the statistically significantly highest mean shear bond strength, which is in accordance with InHae Han et al. [7] due to the blasted silica modified aluminum silicate particles that create silica coat for bonding to composite resin through silane coupling agent.

Other studies by Abushelib et al. [12] ,Markus et al. [18] and Encke et al. [19] stated that the presence of phosphate ester monomer 10-MDP provided stable and strong chemical bond to zirconia because it binds directly to the zirconia oxide layer with high bonding strength. As the Z-prime zirconia primer contains such MDP and provide high bond strength and increase chemical bond strength to zirconia, thus these findings conform to previous studies.

Laser showed the lowest mean shear bond strength which is in accordance with Zanjani et al. [10] who attributed the weak effect of laser is the inability to create surface irregularities and roughness enough to affect the shear bond strength compared to air abrasion. In addition, analysis of the surface of zirconia after laser surface treatment was done by Foxton et al. [20] and revealed dark areas, damaged surface with cracks which is probably due to the melting of the surface using laser.

With Zirconia: Pair-wise comparisons between the surface treatments revealed that Cojet recorded the statistically significantly highest mean shear bond strength which is in accordance with May et al. [21] and this high bond strength was attributed to the action of silica coating of the surface of the zirconia 
making the surface chemically bondable to MDP based resin cements and silane coupling agents and it was also attributed to increased roughness and surface area from the blasting action of silica coated aluminum oxide particles onto the surface of zirconia.

Laser showed the lowest mean shear bond strength which can be explained due to the melting action of the laser to the surface of the ceramic material as mentioned by Foxton et al. [20] who mentioned the presence of damaged surface, dark areas and cracks which were probably due to the melting action of the laser.

With Porcelain: there was a statistically significant difference between surface treatments. Pair-wise comparisons between the surface treatments revealed that Cojet recorded the statistically significantly highest mean shear bond strength. Laser showed the statistically significantly lowest mean shear bond strength, which is in accordance with Saraç et al. [15]. This can be explained as the porcelain has high content of silica $50-60 \%$ by weight and the action of Cojet increased the amount of silica by embedding silica coated aluminum oxide to the surface of the porcelain which resulted in high amount of chemically bondable silica that achieved high bond strength to the silane coupling agent and also can be attributed to the increase in surface area and roughness that resulted from the blasting action of silica coated aluminum oxide to the surface of porcelain which was considered by Saraç et al. the "major" factor for a strong bond [17,19]

In general the laser shear bond strength values were less in the porcelain sub groups than in zirconia sub groups and this can be explained in accordance to Sari et al. [22] in his study that measured light transmission of Er:Yag laser through different ceramic materials and it was found that the light transmission of laser in monolithic zirconia is higher than in porcelain which means the energy of the laser is not absorbed in zirconia with the same degree in feldpsathic porcelain and as a result it will not affect the surface or change its topography as well as the feldpsathic porcelain surface [22-28].

\section{Regarding mode of failure}

Zirconia + Laser showed the highest prevalence of adhesive failure which is conformed with the shear bond strength test values and with previous study of Kirmali et al. [9] as the Er:Cr YSGG group showed high prevalence of adhesive failure in his study (70 $\%$ adhesive failure) as this group showed the lowest mean shear bond strength value [2830].

Porcelain + Cojet showed the highest prevalence of cohesive failure which is in accordance with the shear bond strength test values as the porcelain/Cojet sub group showed the highest shear bond strength and as a result the anticipated failure with such high bond value will be cohesive as the composite/ceramic interface has a high bond strength. Zirconia + Air Abrasion showed the highest prevalence of mixed failure as air abrasion creates surface roughness and irregularities but the shear bond strength values were less than Cojet group which can explain the mixed failure in this sub group as Air abrasion depends mainly on mechanical interlocking without chemical mean of bond while Cojet acts by mechanical and chemical bonding mechanisms [30-35].

The null hypotheses proposed for this study were:

I- LASER surface treatment will not significantly affect shear bond strength compared to other methods.

II-There will be no difference in shear bond strength between different surface treatments with either zirconia or porcelain.

The first null hypothesis was accepted because laser did not significantly improve the shear bond strength when compared to other surface treatment methods.

The second null hypothesis was rejected by the results of shear bond strength testing as it showed that there is a significant difference 
in shear bond strength results when different methods of surface treatments were used. Cojet showed the highest shear bond strength values due to its 2 modes of increasing the bond strength chemically and mechanically while laser showed the least shear bond strength value. In addition, Zirconia showed statistically significantly lower mean shear bond strength than Porcelain [36-42].

There were some limitations in this study as it was an in vitro study without exposure to different oral conditions and oral environment variables as $\mathrm{PH}$, enzymatic changes, different load patterns. In addition the different power outputs of laser might have an effect on the results of shear bond strength. Further clinical trials are recommended to confirm the in vitro results from this study.

\section{CONCLUSION}

Within the parameters used and limitations of this study, it can be concluded that:

1- Cojet surface treatment provided superior shear bond strength in comparison to the tested surface treatment methods and regardless of the ceramic type whether zirconia or porcelain;

2- Porcelain provided superior shear bond strength values in comparison to zirconia regardless of the surface treatment method tested;

3- Porcelain showed higher percentage of cohesive failure that while the mode of failure in zirconia was most commonly adhesive.

\section{Clinical Relevance}

Based on this study, Cojet is recommended as the surface treatment method in case of intraoral repair of fractured bilayered zirconia restoration. In addition, it is recommended to conserve as much feldpsathic porcelain as possible because it offers higher shear bond strength in comparison to zirconia regardless of the surface treatment method used.

\section{Disclosure}

No conflicts of interest.

\section{REFERENCES}

1. Akyl MS, Uzun IH, Bayindir F.Bond strength of resin cement to yttriumstabilized tetragonal zirconia ceramic treated with air abrasion, silica coating, and laser irradiation. Photomed Laser Surg. 2010;28(6):801-8.

2. Uzun IH, Malkoç MA, Polat NT,Öğreten AT. The effect of repair protocols on shear bond strength to zirconia and veneering porcelain. J Adhes Sci Technol. 2016;30(16):1741-53. doi: 10.1080/01694243.2016.1168503.

3. Kirmali 0,Barutcigil Ç, Ozarslan MM, Barutcigil K, Harorlı OT. Repair bond strength of composite resin to sandblasted and laser irradiated Y-TZP ceramic surfaces. Scanning 2015;37(3):186-92. doi: 10.1002/sca.21197.

4. Sailer I,Fehér A, Filser F, Lüthy H, Gauckler L, Schärer P, etal. Prospective clinical study of zirconia posterior fixed partial dentures:3-year follow-up. Quintessence Int. 2006;37(9):685-93.

5. Sailer I,Fehér A, Filser F, Gauckler LJ, Lüthy H, Hämmerle CH. Five-year clinical results of zirconia frameworks for posterior fixed partial dentures. Int $J$ Prosthodont. 2007;20(4):383-8.

6. Aboushelib MN, Kleverlaan CJ, Feilzer AJ. Effect of zirconia type on its bond strength with different veneer ceramics. J Prosthodont. 2008;17(5):401-8. doi: 10.1111/j.1532-849x.2008.00306.x.

7. Han IH,Kang DW, Chung $\mathrm{CH}$, Choe HC, Son MK. Effect of various intraoral repair systems on the shear bond strength of composite resin to zirconia. $J$ Adv Prosthodont. 2013;5(3):248-55. doi:10.4047/jap.2013.5.3.248.

8. Kirmali O, Barutcigil C, Ozarslan M, Barutcigil K, Harorll OT. Repair bond strength of composite resin to sandblasted and laser irradiated Y-TZP ceramic surfaces. The Journal of Scanning Microscopes. 2015;37(3):186-92. doi:10.1002/ sca.21197.

9. Panah FG, Rezai SM, Ahmadian L The influence of ceramic surface treatments on the micro-shear bond strength of composite resin to IPS Empress 2 .J Prosthodont. 2008;17(5):409-14. doi: 10.1111/j.1532-849x.2007.00296.x.

10. Akhavan Zanjani V, Ahmadi H, Nateghifard A, Ghasemi A, Torabzadeh H, Abdoh Tabrizi M et al. Effect of different laser surface treatment on microshear bond strength between zirconia ceramic and resin cement. J Investig Clin Dent. 2015;6(4):294-300. doi: 10.1111/jicd.12105.

11. Fischer J, Grohmann P,Strawarczyk B. Effect of zirconia surface treatments on the shear strength of zirconia/veneering ceramic composites. Dent Mater J. 2008;27(3):448-54.

12. Aboushelib MN, Kleverlaan CJ, Feilzer AJ. Selective infiltration-etching technique for a strong and durable bond of resin cements to zirconia-based materials. J Prosth Dent. 2007;98(5):379-88.

13. Lindgren J, Smeds J, Sjögren G. Effect of surface treatments and aging in water on bond strength to zirconia. Oper Dent. 2008;33(6):675-81. doi: 10.2341/08-12.

14. Gale MS, Darvell BW. Thermal cycling procedures for laboratory testing of dental restorations. J Dent. 1999;27(2):89-99.

15. Saraç D, Saraç YS, Külünk S, Erkoçak A. Effect of various surface treatments on the bond strength of porcelain repair. Int J Periodontics Restorative Dent. 2013;33(4):E120-6. doi:10.11607/prd.1362 
16. Arami S, Hasani Tabatabaei M, Namdar F, Safavi N, Chiniforush N. Shear bond strength of the repair composite resin to zirconia ceramic by different surface treatment. J Lasers Med Sci. 2014;5(4):171-5.

17. Ban S, Sato $\mathrm{H}$, Suehiro $\mathrm{Y}$,Nakanishi $\mathrm{H}$, Nawa M. Biaxial flexure strength and low temperature degradation of Ce-TZP/Al203 nanocomposite and Y-TZP as dental restoratives. J Biomed Mater Res B Appl Biomater. 2008;87(2):492-8. doi:10.1002/jbm.b.31131.

18. Blatz MB, Sadan A, Martin J, Lang B. In vitro evaluation of shear bond strengths of resin to densely-sintered high-purity zirconium-oxide ceramic after longterm storage and thermal cycling. J Prosthet Dent. 2004;91(4):356-62.

19. Encke Bs, Heydecke G, Wolkewitz M, Strub JR. Results of a prospective randomized controlled trial of posterior ZrSiO(4)-ceramic crowns. J Oral Rehabil. 2009;36(3):226-35. doi:10.1111/j.1365/j.1365-2842.2008.01918.x.

20. Foxton RM, Cavalcanti AN, Nakajima M, PileckiP,Sherriff M, Melo L etal. Durability of resin cement bond to aluminium oxide and zirconia ceramics after air abrasion and laser treatment. J Prosthodont. 2011;20(2):84-92 doi:10.1111/j.1532-849x.2010.00678.x.

21. May LG, Passos SP,Capelli DB, Özcan M, Bottino MA, Valandro LF.Effect of silica coating combined to a MDP-based primer on the resin bond to Y-TZP ceramic. J Biomed Mater Res B Appl Biomater. 2010;95(1):69-74. doi: 10.1002/ jbm.b.31684.

22. Sari T, Tuncel İ,Usumez A, GutknechtN. Transmission of Er:YAG Laser Through Different Dental Ceramics. Photomed Laser Surg. 2014;32(1):37-41. doi: 10.1089/ pho.2013.3611.

23. Cengiz-Yanardag E, Yilmaz SK, Karakayal,Salim 0.Effect of different surface treatment methods on micro-shear bond strength of CAD-CAM restorative materials to resin cement. J Adhes Sci Technol. 2018;33(2):110-23. doi: 10.1080/01694243.2018.1514992.

24. Loomans B, Özcan M. Intraoral repair of direct and indirect restorations: procedures and guidelines. Oper Dent. 2016;41(S7):S68-S78.

25. Mirhashemi A, Sharifi N, Moharrami M, Chiniforush N. Evaluation of different types of lasers in surface conditioning of porcelains: a review article. Lasers Med Sci. 2017;8(3):101-11. doi:10.15171/j/ms.2017.19

26. Demirel G, Baltacıoğlu i Influence of different universal adhesives on the repair performance of hybrid CAD-CAM materials. Restor Dent Endod. 2019;44(3):e23. doi: 10.5395/rde.2019.44.e23.

27. Tokar E, Polat S, Ozturk C. Repair bond strength of composite to Er,Cr:YSGG laser irradiated zirconia and porcelain surfaces. Biomed J. 2019;42(3):193-99. doi:10.1016/.jbj.2019.02.001

28. Galvão Ribeiro BR, Galvão Ribeiro Caldas MR, Almeida AA Jr, Fonseca RG, Adabo GL. Effect of surface treatments on repair with composite resin of a partially monoclinic phase transformed yttrium-stabilized tetragonal zirconia. JProsthetDent. 2018;119(2):286-91. doi: 10.1016/.jprosdent.2017.02.014.

29. MumcuE,Erdemir U,Özsoy A, Tekbas-Atay M, Özcan M. Effect of surface conditioning methods on the microtensile bond strength of repair composite to indirect restorative materials. J Adhes Sci Technol. 2019;33(21):2369-84. doi: 10.1080/01694243.2019.1640173.
30. Zakavi F,Mombeini M, Dibazar S, Gholizadeh S. Evaluation of shear bond strength of zirconia to composite resin using different adhesive systems. J Clin Exp Dent 2019;11(3):e257-263. do: 10.4317

31. Shafiei F,FattahZ, Kiomarsi N, Dashti M. Influence of primers and additional resin layer on zirconia repair bond strength. J Prosthodont. 2019;28(7):826-32 do; 10.1111/JOPR.13011.

32. Cristoforides P,Amaral R, May LG, Bottino MA, Valandro LF.Composite resin to yttria stabilized tetragonal zirconia polycrystal bonding: comparison of repair methods. J Oper Dent. 2012;379(3):263-71. doi:10.2341/11-193-L.

33. Yavuz T,Özyllmaz ÖY,Dilber E, Tobi ES, Kiliç HS. Effect of different surface treatments on porcelain-resin bond strength. J Prosthodont. 2017;26(5):44654. doi: $10.1111 /$ jopr.12387.

34. EgilmezF,Ergun G, Cekic-Nagas I,Vallittu PK, Ozcan M, Lassila LVJ.Effect of surface modification on the bond strength between zirconia and resin cement. JProsthodont. 2013;22(7):529-36. doi:10.1111/jopr.12030.

35. Tsuo Y, Yoshida K, Atsuta M. effects of alumina-blasting and adhesive primers on bonding between resin luting agent and zirconia ceramics. Dent Mater J. 2006;25(4):669-74.

36. Luthra R, Kaur P.An insight into current concepts and techniques in resin bonding to high strength ceramics. Aust Dent J. 2016;61(2):163-73. doi: 10.1111/ adj.12365.

37. Yang B, Barloi A, Kern M. Influence of air-abrasion on zirconia ceramic bonding using an adhesive composite resin. Dent Mater 2010;26(1):44-50. doi: 10.10106/j.dental.2009.08.008.

38. Neis CA, Albuquerque NL, Albuquerque Ide S, Gomes EA, Souza-Filho CB, Feitosa VP, et al. Surface treatments for repair of feldspathic, leucite - and lithium disilicate-reinforced glass ceramics using composite resin. Braz Dent J. 2015;26(2):152-5. doi:10.1590/0103-6440201302447.

39. Dilber E, Yavuz T, Kara HB, Ozturk AN. Comparison of the effects of surface treatments on roughness of two ceramic systems. Photomed Laser Surg. 2012;30(6):308-14. doi:10.10.1089/pho.2011.3153

40. Saade J, Skienhe H, Ounsi H, Matinlinna JP,Salameh Z Effect of different combinations of surface treatment on adhesion of resin composite to zirconia. Clin Cosmet Investig Dent. 2019;11:119-29. doi:10.2147/CCIDE.S204986.

41. Liu L, Liu S, Song X, Zhu Q, Zhang W. Effect of Nd: YAG laser irradiation on surface properties and bond strength of zirconia ceramics. Lasers Med Sci. 2015;30(2):627-34. doi:10.1007/s10103-013-1381-7.

42. da Silva Ferreira S, Hanashiro FS, de Souza-Zaroni WC, Turbino ML, Youssef MN. Influence of aluminum oxide sandblasting associated with Nd:YAG or Er:YAG lasers on shear bond strength of a feldspathic ceramic to resin cements. Photomed Laser Surg. 2010;28(4):471-5. doi: 10.1089/pho.2009.2528.

\section{Dr. Ahmed Atef}

(Corresponding address)

Postal Code: 44666

No.184, District35, 10th of Ramadan city, Sharkia, Egypt

Date submitted: 2019 0ct 04

E-mail: Ahmed50862@miuegypt.edu.eg 